\title{
Preface to special issue on cooperation in selfish systems
}

\author{
David Hales • Bruce Edmonds • Ozalp Babaoglu • \\ Paul Spirakis
}

Published online: 25 October 2008

(C) The Author(s) 2008. This article is published with open access at Springerlink.com

Keywords Dynamic network analysis $\cdot$ Network science $\cdot$ Selfish systems ·

Network evolution

The problem of understanding the conditions under which cooperation or altruism can be sustained between interacting selfish entities is a fundamental issue in both biology and the social sciences.

In recent years, there has been an explosion of work utilising agent-based computer simulation to explore novel mechanisms for cooperation. This surge was probably kick-started by the famous "computer tournaments" and related work of Robert Axelrod (1984). Predating this, of course, there is a large body of mathematical game theoretic analysis following in the tradition established by von Neumann and Morgenstern (1944). Historically, this latter approach has tended towards unrealistically strong assumptions concerning the rationality and knowledge of actors. More recently, refinements have addressed systems with slightly less strong assumptions.

\footnotetext{
D. Hales $(\varangle) \cdot$ O. Babaoglu

University of Bologna, Bologna, Italy

e-mail: dave@davidhales.com

O. Babaoglu

e-mail: babaoglu@cs.unibo.it

B. Edmonds

Manchester Metropolitan University, Manchester, UK

e-mail: bruce@cfpm.org

P. Spirakis

Computer Technology Institute, Patras, Greece

e-mail: spirakis@cti.gr
} 
Axelrod looked to biologists, such as Maynard Smith (1982), who had applied evolution to strategies of game interactions between animals. In this approach, strategies were generally simple heuristics, requiring no rationality or common knowledge, selected by evolution where "utility" is interpreted as "fitness". Axelrod's interpretation was, however, not one of biological evolution but social or cultural evolution. The idea is that those strategies that perform better will tend to be imitated by others and hence spread in the population.

Much of the earlier work in this area assumed all agents in a population mixed randomly_so called "mean field" mixing-meaning that any agent could interact with any other over time. The more recent trend has been to study the effect of agents embedded within social or topological structures that limit and mediate their interactions. These structures may be static or may evolve themselves based on interactions between agents.

These kinds of models and results are becoming increasingly relevant for distributed computer systems design. A recent trend in information systems is the emergence of massive and decentralised open systems in which potentially selfish components need to cooperate to achieve their goals. For example, consider the recent popularity of peer-to-peer (P2P) applications over the Internet. Many of these kinds of systems need to self-organise without central control or global information (so as to be robust against interference, for example). Hence, simple heuristics that promote cooperation are potentially very desirable. As a case in point, the currently most popular P2P system, called BitTorrent, ${ }^{1}$ uses a cooperation protocol inspired by the "tit-for-tat" strategy popularised by Axelrod's computer tournaments. It is for these reasons that computer scientists, and particularly distributed systems researchers, are becoming interested in basic cooperation theory and novel mechanisms that facilitate such cooperation.

This special issue is the result of a workshop held over two days (May 27-28) in 2006 at the University of Bologna conference centre in Bertinoro, Italy. The workshop brought together social scientists and computer scientists working on novel cooperation mechanisms from around the world. After the workshop, ten papers were submitted, including an invited paper, for this special issue. From these five papers were selected.

All of the selected papers focus on some aspect of social structure, either static or dynamic, relating how those structures influence cooperation between simple agents playing simple interaction games.

Shutters (2008) presents a thorough analysis of simulations where agents play the ultimatum game on different spatial topologies, with and without punishment sanctions. Edmonds et al. (2008) survey some recent models that produce cooperation through dynamic social structures including tag-based cooperation and evolving networks. Rossi et al. (2008) apply a simple evolving network model to agents playing the "weakest link" game where there is a set of increasing, socially efficient equilibria. They show that the evolving structure selects robustly for socially optimal outcomes. Mollona and Marcozzi (2008) present and compare a set of models of task allocation for firms in a knowledge-based economy. Interestingly these models were

${ }^{1}$ http://www.bittorrent.com. 
derived partially from proposed P2P protocols. Nikoletseas et al. (2008), in an invited paper, present a detailed analysis of a "hawks and doves" game over a graph showing how topology affects the survivability of strategies in the long-run. We feel that these papers collectively show the promise and progress in this area. We look with anticipation for their further development.

Finally, we would like to thank all those who attend the Bertinoro workshop and who submitted papers for this special issue. We also owe a great debt to the anonymous reviewers who conscientiously read and commented on the submitted papers and suggested improvements to the authors. We would like to thank the sponsors of the workshop. ${ }^{2}$ Without their financial support the workshop would not have been possible.

Open Access This article is distributed under the terms of the Creative Commons Attribution Noncommercial License which permits any noncommercial use, distribution, and reproduction in any medium, provided the original author(s) and source are credited.

\section{References}

Axelrod R (1984) The evolution of cooperation. Basic Books, New York

Edmonds B, Norling E, Hales D (2008) Towards the evolution of social structure. J Comput Math Organ Theory. doi:10.1007/s10588-008-9052-2

Mollona E, Marcozzi A (2008) FirmNet: the scope of firms and the allocation of tasks in a knowledgebased economy. J Comput Math Organ Theory. doi:10.1007/s10588-008-9049-8

Nikoletseas S, Raptopoulos C, Spirakis P (2008) The survival of the weakest in networks. J Comput Math Organ Theory. doi:10.1007/s10588-008-9050-2

Rossi G, Arteconi S, Hales D (2008) Evolving networks for social optima in the "Weakest Link Game". J Comput Math Organ Theory. doi:10.1007/s10588-008-9051-1

Shutters S (2008) Strong reciprocity, social structure, and the evolution of fair allocations in a simulated ultimatum game. J Comput Math Organ Theory. doi:10.1007/s10588-008-9053-z

Smith MJ (1982) Evolution and the theory of games. Cambridge University Press, Cambridge

von Neumann J, Morgenstern O (1944) Theory of games and economic behavior. Princeton University Press, Princeton

\footnotetext{
${ }^{2}$ Partially supported by the EU within the 6th Framework Program under contract 001907 (DELIS). Additional support came from the Bertinoro International Center for Informatics (BiCi).
} 